\title{
Engaging Biological Science students in the development of employability skills through creative teaching and peer reviewed action plans
}

\author{
lan J. Turner \\ University of Derby, UK \\ Liz Day \\ University of Derby, UK
}

\begin{abstract}
In this article the authors describe how a creative teaching methodology can encourage students with a Bioscience background to reflect on their understanding of employability. Students were asked to construct personal action plans to show how they could demonstrate their achievement of two Bioscience academic standards that related to employability skills from the Higher Education Academy Subject Benchmarks. These action plans were then critiqued anonymously by their peers.
\end{abstract}

Keywords: employability; Personal Development Planning; PDP; peer review.

\section{Context}

Successful career development to a certain extent depends on how an individual plans for this. Personal Development Planning is a process of reflection on not only achievements in an individual's academic, personal, or professional life but also on areas that need further development (Quality Assurance Agency, 2001), so that plans can be made to enhance an individual's employability (Quality Assurance Agency, 2009; Dearing, 1997). PDP is now a requirement within the UK curricula of higher education (Dearing, 1997) and in this paper the development of employability skills is hinged to the learning experience within the discipline context (Warren, 2002). 
Undergraduate Bioscience courses in the UK are producing a high number of academically capable students but it appears these students according to David Willetts MP, Minister of State for Universities and Science, do not have the skills needed in the workplace. When he addressed the Guardian HE Summit he said that: 'We are producing large numbers of first degree graduates who study biological sciences, $10 \%$ of all first degree graduates, the number's going up, but I still get the life sciences industry saying graduates don't have skills they need, and that's because they haven't done enough practical lab work, or because they haven't done crucial specialisms like molecular biology or toxicology' (Willetts, 2011).

Although Willetts highlighted the graduates' lack of practical skills in this speech, when the Society of Biology (2009) initiated a consultation process prior to an accreditation scheme launch, a different picture emerged. They contacted over 612 current bioscience undergraduates from a range of institutions. In response to questions about the employability aspects of their degrees, 350 respondents (57\%) thought that their degree should make them well or highly prepared for entering the workplace, but less than 200 (33\%) thought that their degrees would actually achieve this aim. In the same consultation exercise recent graduates were asked to identify the three skills they most needed (but did not get) from their degree and current employers of bioscience students were asked to highlight the skills most required (but not found) in current bioscience graduates. The top three skills identified by both groups were the same: communication skills, interpersonal skills (working in a team), critical and analytical thinking. Interestingly the skills identified are generic rather than specialised laboratory skills as highlighted by David Willetts MP.

With the skills gap highlighted by the Society of Biology in mind, the authors designed an employability session for a first year undergraduate module. Employability was already a focus of the curriculum but previous student feedback had found such sessions 'boring' and 'a waste of time'. This session worked on modifying the existing lesson template to engage students with themes relevant to their specific subject area that could be important for their personal development. The aims of this new session were to encourage first year undergraduate Biological Sciences and Zoology students to discuss the concept of employability (and its importance) and to explore how personal perspectives and viewpoints may impact on their employability. The students were encouraged to engage with personal development planning through reflection and asked to write a personal development plan that would be peer reviewed. 


\section{Approach}

\section{Activity one: concept of employability}

The session started by introducing the aims of all the activities to the students and by providing brief contextual information on the importance of developing a range of employability skills so as to be prepared for the competitive arena of the workplace.

Students were initially asked to write what they understood by the term 'employability' on a post-it note, and volunteers from the class were then invited to read out their definitions. There was a wide range of responses (51 in total, $n=52$ ) reflecting individual learners' understanding of the term. The students' individual definitions included 'having determination and work experience', 'getting a range of skills to be an attractive prospect to employers' and 'selling yourself'. Word Cloud analysis (Figure 1) of all the responses highlights that the most common terms used were 'jobs', 'experience', 'skills' and 'qualifications'.

Figure 1. Word Cloud of first year Biology and Zoology undergraduates' definitions of employability. The larger the words the more frequently it occurred in students' responses.

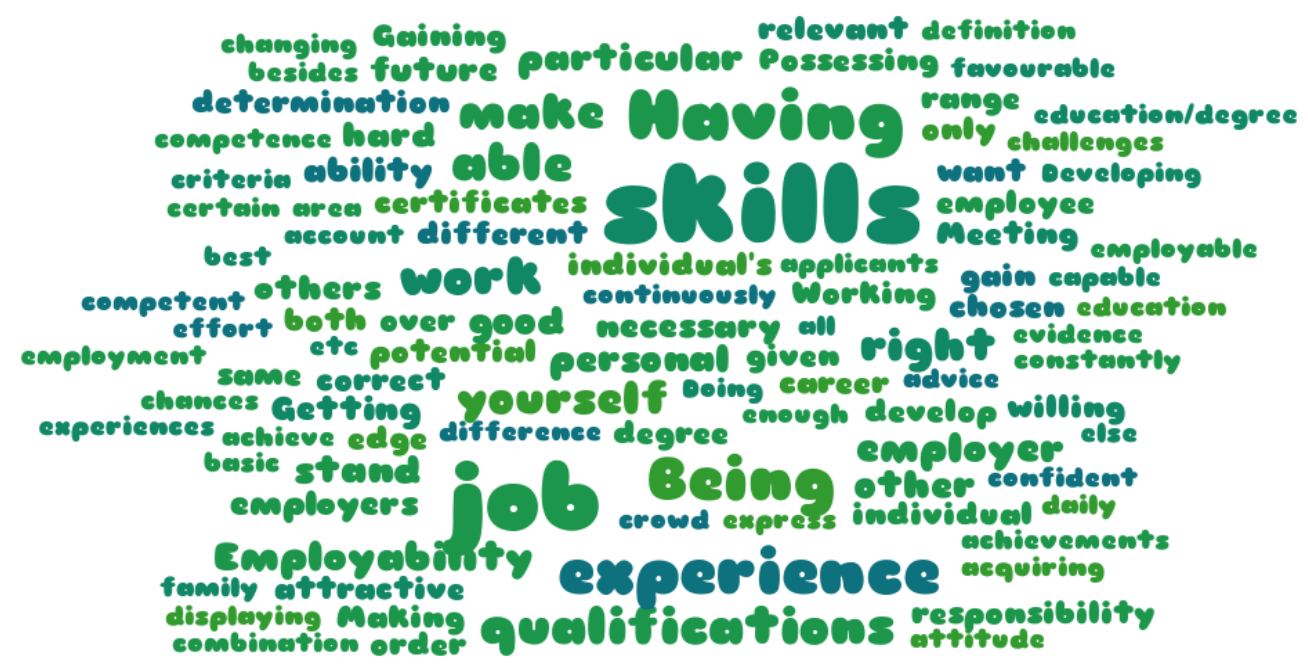

There were three common themes identifiable in the students' responses. The first was the importance of nurturing and tailoring an individual's skills and abilities to the employment of their choice: 'Having the right combination and experience and skills' as well as 'being right for the job'. The second theme was based around the competitiveness of the employment sector and making yourself more employable than a graduate from a similar 
programme 'Being different from others' and 'Making yourself stand out from the crowd'. The third theme was centred on the personal nature of skills development 'You! Only you can make yourself employable and nobody else'. It would seem that the students saw the concept of employability as one that combines their academic qualification with extracurricular skills and experience, as all necessary prerequisites to secure employment.

Students then took part in an employability quiz adapted from a card sort game that encouraged them to think about the term employability in a broader sense (Mortenson and Butcher, 2003). The game lists 24 definitions of employability and challenged the students to think about which of the definitions are 'very much about employability', 'partly about employability', 'maybe or maybe not about employability', 'definitely not about employability' and 'irrelevant to employability'. The students completed this exercise in small groups and then fed back to the whole class. The students reached consensus on some of the definitions, for example, being adept at key skills was seen as very much about employability. Those definitions that were linked to or reflected their own key terms used to define employability (activity one) were much better recognised in the card sort exercise. Some definitions in the exercise resulted in a clear split in students' agreement, for example, 'Employability is part of the contract between the university and the student' was ranked as 'definitely not about employability' by almost $50 \%$ of the students taking part.

\section{Activity two: bridging the gap - employability skills and academic knowledge} Two subject bench mark statements from the QAA Biosciences Academic Standards were identified that were significant to the students in terms of their personal development and that would help then see the link between their academic curriculum and employability skills. The bench mark statements that were selected related to the construction of scientific arguments, the understanding of ethical and social impacts of biological research and also maintaining and enhancing scientific knowledge to better support arguments (Quality Assurance Agency, 2007, Standard 5.8).

Two weeks prior to this session students had attended a lecture that examined the evolution versus creationism debate; a recap was presented to the students in this session. The recap lecture briefly outlined the fundamental concepts of the debate and posed several social considerations. Students were asked to consider how a bioscientist 
would deliver the material to a range of audiences e.g. scientists, the general public and children who went to a Church of England school. The students were then asked in pairs to debate the following statement: 'Teachers should put their beliefs and values to one side and present a variety of different perspectives on a theme even if this contradicts their own value system'.

During the debate some students exhibited firm views about what they would teach and why they would choose particular theories. They appeared to be unable to recognise or acknowledge any constraints that would impact on what they believed should be taught. Other students took cognisance of the different cultures they might be exposed to and reflected on the impact of what they had to say on others. Students were also asked to consider how their personal response to the statement might be perceived from different perspectives, for example, that of a parent, legal representative, religious leader and an employer. Students debated this topic in earnest and the majority of students were able to reflect on their initial response. Although this often did not change their opinion it did lead them to realisation they must be able to defend their views with a reasoned argument or their views would not be heard at all.

\section{Activity three: action planning and critique}

After the debate students were given time to reflect in pairs on the question: 'What do I need to do (personally, academically or practically) to develop or enhance my ability to appreciate other people's views and their different perspectives on life?'. To help them achieve this we asked the students to generate a Personal Development Plan that included their personal goals, an action plan to achieve these goals and to identify any support needed to realise their goals.

The students were asked to submit their Personal Development Plan via an electronic submission and retrieval system which was organised with timelines that were given to the students in advance (Figure 2). The system was designed so that once all the plans had been submitted they could be retrieved electronically and anonymously by a peer from the same student group. 
Students were then asked to critique the action plans by reference to prescribed questions:

1. Does the statement identify personal, academic and practical aims? (Goals)

2. Is there a clear indication of how these aims are to be achieved? (Action and resources)

3. Would you like to make any comments regarding the action plan? (Support)

Critiques were uploaded via the same system and at the end of the time scale (Figure 2) students could retrieve their personal critique. The entire system was anonymous and student privacy was assured in the briefing notes given to the students explaining the activity. The teaching team were able to identify the students' work so that additional support and praise could be offered appropriately. Students were required to participate in this activity (part of a summative assessment) and a pass/fail grade was awarded for completing an action plan and a critique.

Figure 2. A flow diagram illustrating the timescales of activities students were required to undertake following the employability session.

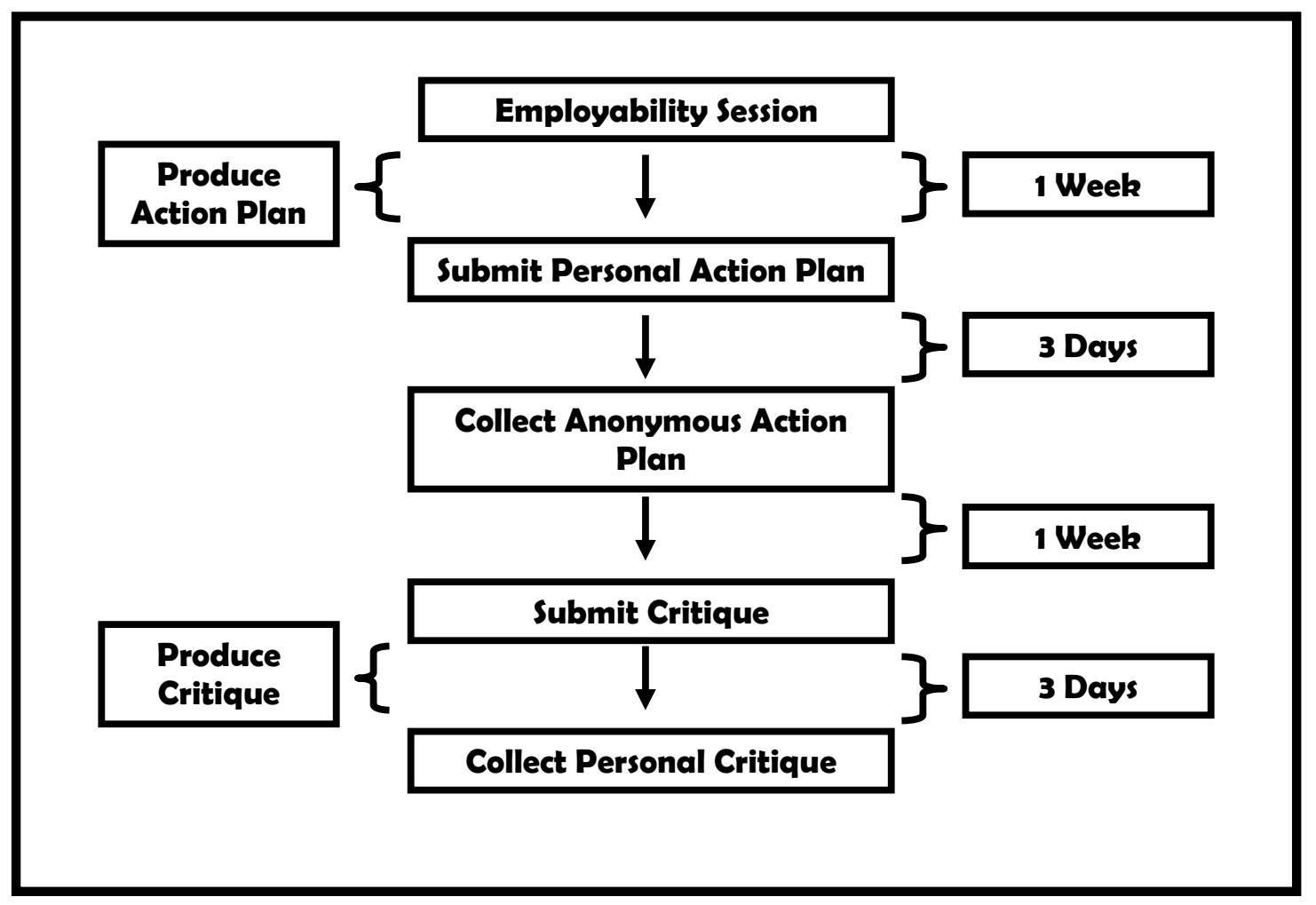




\section{Summary of action plans and critiques}

There were 52 students in the module and of these 50 submitted an action plan. The range of structures to the plans was wide, for example, essay format, charts that identified columns for personal and academic aims with a column asking how and when these would be achieved, some included an extra column for practical aims (see example of typical action plans in the appendix ). Several students identified the steps they needed to take to progress; the task to be undertaken, how to achieve the task and the end goal. They organised this by devising columns for long term goals and short term goals, how to achieve my long term goal, actions, how and when. Not all of the students followed the instructions and a small number produced an action plan that was very generic, for example, a personal statement about their extra-curricular activity or modified version of their curriculum vitae. Clearer instruction and exemplar action plans may have helped the students to produce a more considered action plan. Whilst the instructions must include structural guidance it is important that they do not hinder the student's creativity.

Of the 50 students who submitted action plans, 34 submitted a critique. The critiques ranged from comments relating to suggestions on how to produce a timetable to highlight free time (to encourage time management), to very positive comments that clearly indicated that the peer reviewer was impressed with the format of the plan and was going to incorporate some of the ideas into their own at a later date. Some reviewers asked many questions in a supportive manner and gave constructive feedback. The most common words (see Figure 3 ) in the critiques were 'action' and 'plan' which is to be expected as students were directly commenting on what they saw before them. Other common words include 'academic' and 'personal' which reflects the two main areas in which the students grouped their personal targets, 'achieve(d)' and 'practical' also occur frequently which may relate to the realisation of these targets (see example critique in appendix). Sixteen students did not complete the critique element of the exercise. To ensure all students received feedback on their action plans the teaching team critiqued the remaining students' work. As this work was linked to a formative assessment students had to resubmit work. This took the form of a personal reflection on the action plan and critique process. It appears many of the non-submissions were due to students being unsure 'what to say'. In future lessons the guidance on providing critiques (and possibly exemplar critiques) would be provided to students at the onset of the activity. 
Figure 3. Word Cloud of first year Biology and Zoology undergraduates' critiques of peers' action plans. The larger the words the more frequently it occurred in students' responses.

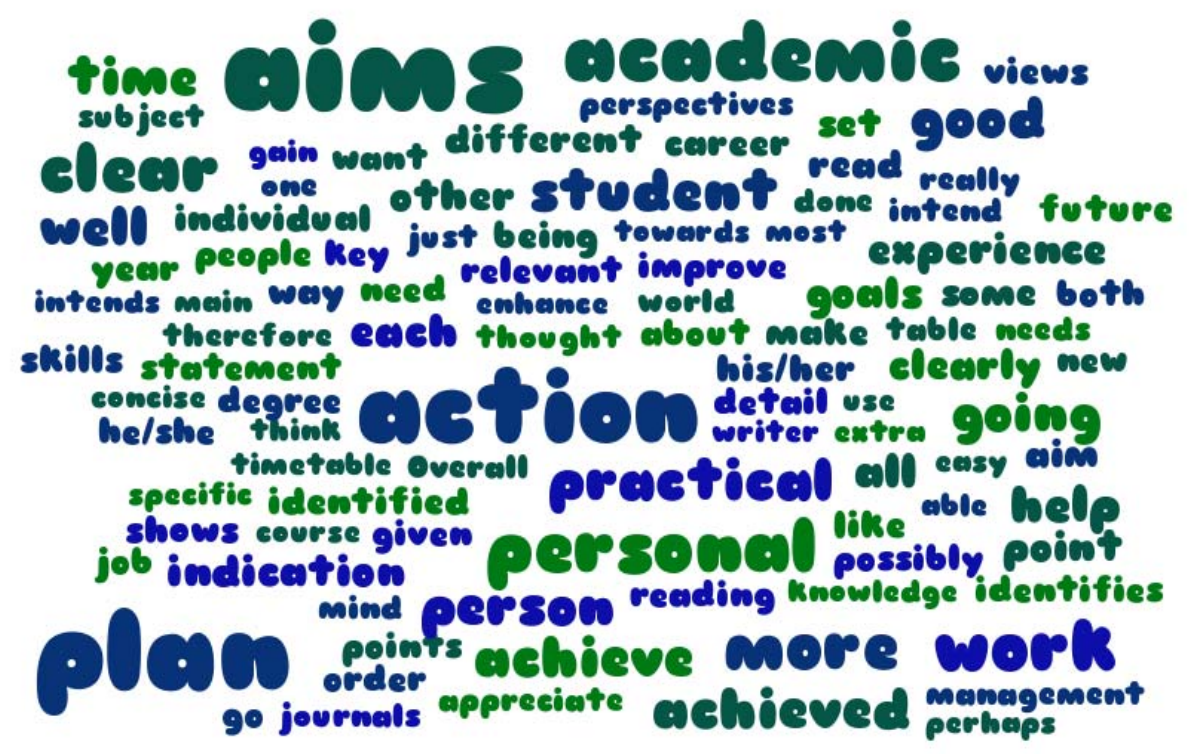

\section{Conclusion}

Students need to recognise that through their academic university experience new skills and attributes can be acquired that will make an important contribution to their employability. Furthermore, the exercise shows that employability is not just about having subject knowledge. The content of the lecture was chosen to highlight to students that lectures in addition to other academic material can contribute to the development of a wide range of employability skills. In addition it shows that employability skills are part of the student's on-going development as scientists. Creative teaching approaches encourage students to link their generic and disciplinary skills and highlight the importance of the students' role in developing these skills.

Based on student uptake and engagement of the action plan/critique exercise and informal communication with students, it is clear that this new exercise was well received by the majority of students. The full impact of such activities can only be truly assessed by a continuing theme of employability in subsequent stages of their degree and continually revisiting their action plans. 


\section{Acknowledgments}

The authors would like to thank Elizabeth Claridge for help with the session and all the students in the class who allowed us to use their action plans.

\section{References}

Dearing, R. (1997) The Dearing Report - National Committee of Inquiry into Higher Education. Hayes: NCIHE.

Mortenson, R. and Butcher, V. (2003) Enhancing Student Employability Coordination Team (ESECT). Available at:

http://www.heacademy.ac.uk/resources/detail/resource database/SNAS/Enhancing Student Employability Coordination Team ESECT (Accessed: 26 March 2012).

Quality Assurance Agency (2001) Guidelines for HE progress files. London: QAA. http://www.qaa.ac.uk/Publications/informationAndGuidance/Pages/Guidelines-forHE-Progress-Files.aspx (Accessed: 26 March 2012).

Quality Assurance Agency (2007) Bioscience subject benchmark statements. Gloucester: QAA. http://www.qaa.ac.uk/Publications/InformationAndGuidance/Pages/Subjectbenchmark-statement-Biosciences.aspx (Accessed: 26 March 2012).

Quality Assurance Agency (2009) Personal Development Planning: guidance for institutional policy and practice in higher education. Gloucester: QAA. http://www.qaa.ac.uk/Publications/InformationAndGuidance/Pages/Personaldevelopment-planning-guidance-for-institutional-policy-and-practice-in-highereducation.aspx (Accessed: 26 March 2012).

Society of Biology (2009) Launch and consultation: framework for the accreditation of UK biosciences degrees. Available at: http://www.societyofbiology.org/education/hei/accreditation/accreditationlaunch (Accessed: 6 February 2012). 
Warren, D. (2002) 'Curriculum design in a context of widening participation in higher education', Arts and Humanities in Higher Education, 1(1), pp. 85-89.

Willetts MP, D. (2011) Public address speech, Guardian HE Summit. America Square Conference Centre, London 16 March 2011.

\section{Author details}

Dr Ian Turner is a Senior Lecturer in Biology and Forensic Science and the Learning and Teaching Fellow for the School of Science at the University of Derby. He is also the Chairman of the Derbyshire Branch of the British Science Association.

Liz Day was a Senior Lecturer in Nursing and Teaching Fellow for Employability Skills and Personal Development Planning at the University of Derby. She is currently Academic Lead for Institutional Strategy and Internationalisation at the Higher Education Academy, York. 


\section{Appendix}

\section{Example Unmodified Action Plan and Critique 1}

\section{Action Plan}

As a person, I find myself already quite capable at accepting and/or judging other people's views and perspectives. I can maintain objective in situations where two or more views are given on a subject, and I am able to conclude on my own an unbiased view of the subject. There is always room for improvement however, so I have come up with a list of ways in which I can improve on the matter.

Personally, I think I could attend more social meetings amongst people whose views on things differ from my own. By listening to and trying to understand all sides to any particular story, I would be able to grow mentally and expand my own views. To achieve this, I plan to visit social meetings amongst other people on my course and listen to their views on different subject matter.

Academically, I could improve by attending scientific meetings and perform research into topics that are relevant to my course. By doing this, I can gain a better knowledge of my subject area and be more capable in lectures and practical work.

Practically, I could go to catch up seminars on Monday afternoons and learn more about subject areas I do not fully understand.

\section{Critique}

I think that personal, academic and practical aims are clearly separated, although each one of these is still heavily linked to just university work and academic studies. For instance going to seminars and attending meetings will help with academic studies not personal and practical development. Researching into and attending relevant meetings would aid academic and possibly social development although socialising with other people and joining other extra-curricular groups would broaden both social and general skills.

Expanding work experience will help with employability and again with general skills such as time management and people-skills. 


\section{Example Unmodified Action Plan and Critique 2}

\section{Action Plan}

To develop and enhance my ability to appreciate other views and perspectives in my studies, I need to research a large number of resources in order to obtain as much information and as many viewpoints as possible. This can be done by not just relying on notes and facts given to me in lectures and on core text books, but by reading around on subjects - for instance researching journals, books in the library, internet resources and also sharing views with my peers. By having a wide range of opinions available, I will be able to consider them and appreciate their validity even if I don't agree with them myself.

In order to achieve this, I need to research around the given subjects after each lecture, making use of the wide range of resources available to me, and discuss my opinions with my peers and listen to and consider their views. This will enable me to develop both academically and practically and will benefit my studies over the forthcoming years and in my chosen career path after my academic studies.

\section{Critique}

This action plan clearly identifies both personal and academic aims which will be pursued throughout the academic year. How these targets will be achieved has been successfully identified and clearly set out.

I personally like the way your action plan blends individual and academic development (how you intend to include your peers in research).

\section{Example of Unmodified Action Plan and Critique 3}

\section{Action plan}

Personally I will have to motivate myself to work in a structured and effective fashion. Personal motivation is an important factor of academic achievement. For motivation I will have to look for aspects which I find interesting in the subject, as points of interest will lead to personal motivation. Topics of interest can be found through research of the subject, such as reading of textbooks, scientific magazines, and journals. Through this research I will not only be motivating myself personally, but also increasing my knowledge and understanding, thus I will gain appreciation for new areas and different views of the 
subject. Other methods of gaining knowledge can be obtained through practical exercises; such methods may include experiments, discussions with classmates, study groups. Social interaction through discussion and study can also act as motivational factor for me personally.

The key aspect of gaining appreciation for other views and perspectives is knowledge. By gaining knowledge of a subject one discovers new information/perspectives and through critical observation, which is primarily a personal process, one can accept or open up to potential new ways of thinking.

\begin{tabular}{|l|l|l|}
\hline Personal & Academic & Practical \\
\hline Increase of knowledge & Textbooks & Study groups \\
\hline Increase of Understanding & Scientific magazines & Discussions \\
\hline Effectiveness & Journals & Experiments \\
\hline Motivation & Documentary's & \\
\hline $\begin{array}{l}\text { An increase in knowledge through practical and academic exercises will lead } \\
\text { to an increase in appreciation of other views and perspectives }\end{array}$ \\
\hline
\end{tabular}

\section{Critique}

1. Shows personal, academic and practical methods to achieve the ability to appreciate other views and perspectives.

2. A clear and ordered account of how to achieve their aims.

3. Personal Comments:

- Good grammar.

- Shows thorough knowledge and understanding of the task set.

- Has a clear and structured plan that will help them succeed in the long run.

- Will most likely benefit from using this action plan. 